\title{
Kobieta w wieku 61 lat z chorobą wieńcową, hipercholesterolemią rodzinną i zespołem metabolicznym - znaczenie przestrzegania zaleceń terapeutycznych
}

\section{A 61-year-old woman with coronary artery disease, familial hypercholesterolemia and metabolic syndrome - the role of compliance}

\author{
Anna Kowalczys, Agnieszka Mickiewicz, Marcin Gruchała
}

I Katedra i Klinika Kardiologii Gdańskiego Uniwersytetu Medycznego

\section{Streszczenie}

Pacjentka w wieku 61 lat, obciążona ciężkim, źle kontrolowanym nadciśnieniem tętniczym, chorobą wieńcową, heterozygotyczną hipercholesterolemią rodzinną (FH), zespołem metabolicznym, licznymi schorzeniami towarzyszącymi, po wielu przezskórnych interwencjach wieńcowych i naczyniowych, została przyjęta do kliniki z powodu nasilenia dolegliwości dławicowych. W badaniu angiograficznym tętnic wieńcowych uwidoczniono istotne hemodynamicznie zwężenie w gałęzi okalającej, a następnie wykonano angioplastykę tętnicy z implantacją stentu powlekanego lekiem, uzyskując dobry efekt zabiegu. W badaniach laboratoryjnych stwierdzono nadal podwyższone stężenie cholesterolu frakcji LDL. W wywiadzie stwierdzono, że chorą poddawano terapii LDL-aferezą, którą przerwano z powodu 2-krotnego udaru niedokrwiennego mózgu z niedowładem połowiczym oraz afazją. Zmodyfikowano leczenie farmakologiczne, zalecono kontrolę i ponowne rozważenie wskazań do terapii LDL-aferezami lub inhibitorem PCSK-9. Uzyskano poprawę w zakresie przestrzegania zaleceń terapeutycznych (compliance) i potwierdzono dobrą kontrolę ciśnienia tętniczego. Przedstawiony niżej przypadek przybliża możliwości wykorzystania różnych strategii terapeutycznych u pacjentów z FH oraz podkreśla kluczową rolę compliance w kontroli czynników ryzyka sercowo-naczyniowego, zwłaszcza nadciśnienia tętniczego.

Słowa kluczowe: choroba wieńcowa, hipercholesterolemia rodzinna, zespół metaboliczny, nadciśnienie tętnicze, przestrzeganie zaleceń terapeutycznych

Folia Cardiologica 2017; 12, supl. B: B13-B17

\section{Wstęp}

Nadciśnienie tętnicze i hipercholesterolemia należą do najważniejszych czynników ryzyka schorzeń układu sercowo-naczyniowego. Mimo zwiększenia skuteczności prewencji pierwotnej i wtórnej zarówno odsetek chorych z nieleczonym lub niedostatecznie kontrolowanym nadciśnieniem tętniczym, jak i dyslipidemią w polskiej populacji nadal są wysokie [1]. Współistnienie zespołu metabolicznego znacząco przyspiesza rozwój miażdżycy i jej powikłań. Po- niżej przedstawiono przypadek kliniczny leczonej w klinice kardiologii 61-letniej chorej z miażdżycą uogólnioną, heterozygotyczną hipercholesterolemią rodzinną ( $\mathrm{FH}$, familial hypercholesterolemia) i innymi obciążeniami.

\section{Opis przypadku}

Chora w wieku 61 lat, obciążona chorobą wieńcową i licznymi schorzeniami towarzyszącymi, została przyjęta do kliniki w celu wykonania koronarografii z powodu na-

Adres do korespondencji: lek. Anna Kowalczys, I Katedra i Klinika Kardiologii, Gdański Uniwersytet Medyczny, ul. Dębinki 7, 80-211 Gdańsk, e-mail: anna.roz@gumed.edu.pl 
silenia dolegliwości dławicowych (stopień III w klasyfikacji zaawansowania dławicy piersiowej opracowanej przez Kanadyjskie Towarzystwo Kardiologiczne [CCS, Canadian Cardiovascular Society]) od około 3 miesięcy. W wywiadzie stwierdzono ponadto: stan po zawale serca i 14 przezskórnych interwencjach wieńcowych, stan po dwóch udarach mózgu z lewostronnym niedowładem połowiczym, stan po implantacji stentów do obu tętnic szyjnych oraz przezskórnej angioplastyce lewej tętnicy pachowej, miażdżyce tętnic kończyn dolnych, heterozygotyczną FH (mutacja genu dla apolipoproteiny $B$ [apoB]), nadciśnienie tętnicze, napadowe migotanie przedsionków, cukrzycę typu 2, otyłość (wskaźnik masy ciała [BMI, body mass index] 32 $\mathrm{kg} / \mathrm{m}^{2}$ ) oraz przewlekłą obturacyjną chorobę płuc. Wywiad rodzinny był obciążający w kierunku hipercholesterolemii oraz choroby wieńcowej. Pacjentka stosowała następujące leki: kwas acetylosalicylowy $(75 \mathrm{mg} / \mathrm{d}$.), klopidogrel (75 mg/d., riwaroksaban (15 mg/d.), betaksolol (20 $\mathrm{mg} / \mathrm{d}$.), preparat złożony z walsartanu i hydrochlorotiazydu (160/25 mg/d.), torasemid (20 mg/d.), rosuwastatynę (30 $\mathrm{mg} / \mathrm{d}$.), ezetimib (10 mg/d.), metformine (1700 mg/d.), pantoprazol $(20 \mathrm{mg} / \mathrm{d}$.), teofilinę $(150 \mathrm{mg} / \mathrm{d}$.) oraz leki wziewne (bromek tiotropium $1 \times / d$. i salmeterol z flutykazonem $2 \times / d$.). W wywiadzie stwierdzono, że chora była 11-krotnie poddana zabiegom LDL-aferezy metodą podwójnej kaskadowej filtracji (DFPP, double filtration plasmapheresis) (tab. 1). Z powodu wystąpienia dwóch udarów mózgu z następczym lewostronnym niedowładem połowiczym na tle źle kontrolowanego nadciśnienia tętniczego terapia LDL-aferezą została przerwana 3 miesiące przed przedstawioną hospitalizacją. Przed kwalifikacją chorą poddano pełnej diagnostyce, na podstawie której wykluczono wtórną przyczynę opornego nadciśnienia tętniczego. Modyfikacja leczenia farmakologicznego (4 leki hipotensyjne) nie przyniosła oczekiwanej poprawy. Wobec powyższego, mimo zapewnień chorej o regularnym przyjmowaniu leków, wysunięto podejrzenie nieprzestrzegania zaleceń terapeutycznych. Podczas jednej z planowych hospitalizacji poproszono pacjentkę o przyjmowanie leków hipotensyjnych w obecności personelu medycznego uzyskując prawidłową kontrolę ciśnienia tętniczego (RR). Zaangażowanie rodziny do przygotowywania leków i podawania ich chorej przyczyniło się do uzyskania trwałej poprawy kontroli nadciśnienia. Na podstawie analizy wartości RR pochodzących z domowych pomiarów (średnio 125/80 mm Hg) oraz wykonanych w trakcie leczenia w klinice potwierdzono skuteczność terapii hipotensyjnej. W badaniu elektrokardiograficznym (EKG) stwierdzono miarowy rytm zatokowy, wynoszący $65 /$ min oraz cechy przebytego zawału ściany dolnej. W badaniu echokardiograficznym uwidoczniono przerost mięśnia lewej komory, powiększony lewy przedsionek oraz cechy przebytego zawału ściany dolnej, frakcja wyrzutowa lewej komory (LVEF, left ventricular ejection fraction) mieściła się w zakresie 50-55\%. Wykonano koronarografię, w której potwierdzono obecność istotnego hemodynamicznie przewężenia w gałęzi okalającej lewej tętnicy wieńcowej, a następnie angioplastykę z implantacją stentu powlekanego lekiem, uzyskując dobry efekt angiograficzny. W lipidogramie przy przyjęciu do kliniki zwracało uwage nadal podwyższone stężenie cholesterolu frakcji LDL (low-density lipoprotein) $(103 \mathrm{mg} / \mathrm{dl})$, niemniej w mniejszym stopniu niż na początku podjętego leczenia, co powiązano z poprawą przestrzegania zaleceń (compliance) (tab. 1). W dalszym postępowaniu zalecono chorej zwiększenie dawki rosuwastatyny do $40 \mathrm{mg} /$ dobę i ponowną ocenę lipidogramu oraz aktywności aminotransferaz asparaginianowej (AspAT, aspartate aminotransferase) i alaninowej (ALAT, alanine aminotransferase) oraz kinazy kreatyny za około 3 miesiące. W przypadku utrzymywania się podwyższonego

Tabela 1. Wyniki lipidogramu chorej bezpośrednio przed aferezami i po nich oraz przy opisanym przyjęciu do kliniki

$\begin{array}{lccccc}\text { Parametr } & \begin{array}{c}\text { Przed pierwszą } \\ \text { LDL-aferezą, } \\ \text { leczenie statyną } \\ \text { i ezetimibem }\end{array} & \begin{array}{c}\text { Po pierwszej LDL- } \\ \text {-aferezie, leczenie } \\ \text { statyną } \\ \text { i ezetimibem }\end{array} & \begin{array}{c}\text { Przed ostatnią } \\ \text { LDL-aferezą, } \\ \text { leczenie statyną } \\ \text { i ezetimibem }\end{array} & \begin{array}{c}\text { Po ostatniej LDL- } \\ \text {-aferezie, leczenie } \\ \text { statyną } \\ \text { i ezetimibem }\end{array} & \begin{array}{c}\text { Przy przyjęciu do } \\ \text { kliniki, } 3 \text { miesiące } \\ \text { po ostatniej } \\ \text { LDL-aferezie, } \\ \text { leczenie statyną } \\ \text { i ezetimibem }\end{array} \\ \begin{array}{l}\text { Stężenie cholesterolu } \\ \text { całkowitego }\end{array} & 237 & 85 & 260 & 80 & 167 \\ \begin{array}{l}\text { [mg/dl] } \\ \text { Stężenie triglicerydów } \\ \text { [mg/dl] }\end{array} & 101 & & & 60 & 106 \\ \begin{array}{l}\text { Stężenie cholesterolu } \\ \text { frakcji HDL [mg/dl] }\end{array} & 37 & 62 & 100 & 21 & 43 \\ \begin{array}{l}\text { Stężenie cholesterolu } \\ \text { frakcji LDL [mg/dl] }\end{array} & 180 & 14 & 41 & 47 & 103\end{array}$

HDL (high-density lipoproteins) - lipoproteiny o wysokiej gęstości; LDL (Jow-density lipoproteins) - lipoproteiny o niskiej gęstości 
stężenia cholesterolu frakcji LDL (tj. $\geq 70 \mathrm{mg} / \mathrm{dl}$ ) zalecono rozważenie możliwości ponownego wdrożenia leczenia LDL-aferezami lub inhibitorem konwertazy proproteiny subtylizyny/keksyny typu 9 (PCSK-9, proprotein convertase subtilisin/kexin type 9). Schemat najważniejszych wizyt i hospitalizacji chorej przedstawiono na rycinie 1.

\section{Omówienie}

U chorych z przedwczesną, objawową miażdżycą, dodatnim wywiadem rodzinnym w kierunku przedwczesnej choroby wieńcowej oraz wysokim stężeniem cholesterolu frakcji LDL należy przeprowadzić diagnostykę w kierunku

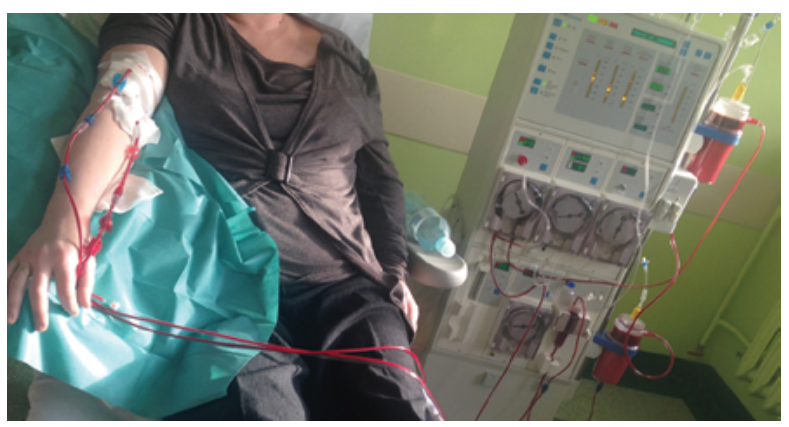

Rycina 1. Chora w trakcie zabiegu LDL-aferezy (zdjęcie własne); LDL (low-density lipoproteins) - lipoproteiny o niskiej gęstości dyslipidemii rodzinnej [2] (tab. 2). Podobnie postąpiono u przedstawionej chorej, potwierdzając kliniczne rozpoznanie FH obecnością mutacji genu apoB. Niestety, u większości chorych z FH choroba jest wciąż zbyt późno rozpoznawana, a tym samym leczona najczęściej w momencie wystąpienia jej powikłań. Heterozygotyczna FH występuje z częstością 1/200-500 i jest zaburzeniem jednogenowym (w 95\% dotyczy genu LDLR) dziedziczonym autosomalnie dominująco, objawiającym się przedwczesnym rozwojem chorób układu sercowo-naczyniowego. Należy jednak pamiętać, że stopień zaawansowania miażdżycy zależy od wielu czynników, dlatego może być różny u chorych z identyczną mutacją. Mutacja genu apoB, którą rozpoznano w przedstawionym przypadku, występuje u 4-5\% pacjentów z FH i prowadzi do defektu wiązania LDL z receptorem, a tym samym wzrostu wartości cholesterolu frakcji LDL we krwi [2]. Do najważniejszych celów leczenia chorych z FH należą zmniejszenie śmiertelności z przyczyn sercowo-naczyniowych oraz częstości występowania zdarzeń sercowo-naczyniowych [2]. Podstawą leczenia farmakologicznego jest terapia tak zwaną silną statyną (rosuwastatyną lub atorwastatyną), zwykle w połączeniu z ezetimibem. Jednak u niektórych chorych nie udaje się uzyskać optymalnej kontroli profilu lipidowego, wówczas warto rozważyć zastosowanie LDL-aferezy (ryc. 2, tab. 3 [3]). Zabiegi LDL-aferezy umożliwiają nie tylko szybkie, skuteczne i bezpieczne obniżenie stężenia

Tabela 2. Kryteria rozpoznawania hipercholesterolemii rodzinnej na podstawie Dutch Lipid Clinic Network (zmodyfikowano na podstawie [2])

\begin{tabular}{|c|c|}
\hline Wywiad rodzinny & Punktacja* \\
\hline Krewni pierwszego stopnia z przedwczesną chorobą wieńcową (kobiety < 60. rż., mężczyźni < 55. rż.) & 1 \\
\hline Krewni I stopnia ze stężeniem cholesterolu frakcji LDL > 190 mg/dl & 1 \\
\hline Krewni I stopnia z żółtakami ścięgien i/lub rąbkiem rogówkowym & 2 \\
\hline Dzieci i młodzież w wieku < 18 lat ze stężeniem cholesterolu frakcji LDL > 155 mg/dl & 2 \\
\hline \multicolumn{2}{|l|}{ Wywiad kliniczny } \\
\hline Przedwczesna choroba wieńcowa & 2 \\
\hline Przedwczesna choroba naczyń mózgowych lub obwodowych & 1 \\
\hline \multicolumn{2}{|l|}{ Badanie przedmiotowe } \\
\hline Żółtaki ścięgien & 6 \\
\hline Rąbek rogówkowy & 4 \\
\hline \multicolumn{2}{|l|}{ Stężenie cholesterolu frakcji LDL [mg/dl] ([mmol/l]) } \\
\hline • > $330(>8,5)$ & 8 \\
\hline • $250-329(6,5-8,4)$ & 5 \\
\hline • $190-249(5,0-6,4)$ & 3 \\
\hline - $155-189(4,0-4,9)$ & 1 \\
\hline \multicolumn{2}{|l|}{ Badanie genetyczne } \\
\hline Mutacja genu receptora LDLR, apoB lub PCSK-9 & 8 \\
\hline
\end{tabular}

*Rozpoznanie: pewne > 8 pkt., prawdopodobne 6-8 pkt., możliwe 3-5 pkt., niepotwierdzone < 3 pkt.; LDL (low-density lipoproteins) - lipoproteiny o niskiej gęstości; PCSK9 (proprotein convertase subtilisin/ kexin type 9) - konwertaza proproteiny subtylizyny/keksyny typu 9 
Pierwsza hospitalizacja w klinice kardiologicznej z powodu zawału serca

\begin{tabular}{|c|c|}
\hline Angioplastyka tętnic wieńcowych & $\begin{array}{c}\text { Leczenie farmakologiczne } \\
\text { Diagnostyka w kierunku hipercholesterolemii rodzinnej }\end{array}$ \\
\hline & \\
\hline \multicolumn{2}{|c|}{ Liczne hospitalizacje w celu wykonania angioplastyki tętnic wieńcowych } \\
\hline Nowe zmiany miażdżycowe w tętnicach wieńcowych & Restenozy w stentach \\
\hline \multicolumn{2}{|c|}{ Hospitalizacja w celu zdiagnozowania przyczyn opornego ciśnienia tętniczego } \\
\hline Wykluczenie wtórnych przyczyn nadciśnienia tętniczego & Modyfikacja leczenia farmakologicznego \\
\hline \multicolumn{2}{|c|}{ Wizyty kontrolne w poradni dla dorosłych z hipercholesterolemią rodzinną } \\
\hline Optymalizacja leczenia farmakologicznego & Kwalifikacja do leczenia metodą LDL-aferezy \\
\hline \multicolumn{2}{|c|}{ Hospitalizacje w klinice kardiologii w celu przeprowadzenia zabiegów LDL-aferezy } \\
\hline 11 zabiegów LDL-aferezy & $\begin{array}{l}\text { Aferezy przeprowadzono metoda podwójnej kaskadowej } \\
\text { hemofiltracji (DFPP, double filtration plasmapheresis) }\end{array}$ \\
\hline \multicolumn{2}{|c|}{ Hospitalizacje na oddziale neurologicznym z powodu dwóch udarów mózgu } \\
\hline $\begin{array}{l}\text { Udary niedokrwienne na tle źle kontrolowanego nadciśnienia } \\
\text { tętniczego powikłane niedowładem połowiczym prawostronnym }\end{array}$ & Przerwanie zabiegów LDL-aferezy \\
\hline \multicolumn{2}{|c|}{ Hospitalizacja kontrolna w celu rozważenia wskazań i bezpieczeństwa ponownych zabiegów LDL-aferezy } \\
\hline $\begin{array}{l}\text { Zaangażowanie personelu i rodziny } \\
\text { w przygotowywanie i podawanie leków chorej }\end{array}$ & Uzyskanie znaczącej poprawy kontroli nadciśnienia tętniczego \\
\hline \multicolumn{2}{|c|}{ Hospitalizacja w klinice kardiologicznej z powodu nasilenia dławicy } \\
\hline $\begin{array}{l}\text { Angioplastyka gałęzi okalającej } \\
\text { z implantacją stentu powlekanego lekiem }\end{array}$ & $\begin{array}{l}\text { Potwierdzenie dobrej kontroli ciśnienia tętniczego } \\
\text { oraz znaczna poprawa kontroli stężenia lipidów }\end{array}$ \\
\hline
\end{tabular}

Rycina 2. Schemat najważniejszych wizyt kontrolnych i hospitalizacji chorej; LDL (Iow-density lipoproteins) - lipoproteiny o niskiej gęstości

Tabela 3. Wskazania do LDL-aferezy (na podstawie [3])

Homozygotyczna hipercholesterolemia rodzinna ze stężeniem cholesterolu frakcji LDL $\geq 300 \mathrm{mg} / \mathrm{dl}$

Heterozygotyczna hipercholesterolemia rodzinna ze stężeniem cholesterolu frakcji LDL $\geq 300 \mathrm{mg} / \mathrm{dl}$ i $\leq 1$ czynnikiem ryzyka choroby wieńcowej

Heterozygotyczna hipercholesterolemia rodzinna ze stężeniem cholesterolu frakcji LDL $\geq 200 \mathrm{mg} / \mathrm{dl} \mathrm{i} \geq 2$ czynnikami ryzyka choroby wieńcowej lub stężeniem $L p(a) \geq 50 \mathrm{mg} / \mathrm{dl}$

Heterozygotyczna hipercholesterolemia rodzinna ze stężeniem cholesterolu frakcji LDL $\geq 160 \mathrm{mg} / \mathrm{dl}$ i udokumentowaną chorobą wieńcową lub cukrzycą

LDL (low-density lipoproteins) - lipoproteiny o niskiej gęstości; Lp (lipoprotein) - lipoproteina 
cholesterolu we krwi, ale również wywierają korzystny wpływ na poprawę funkcji śródbłonka, perfuzji naczyń wieńcowych i obwodowych oraz zmniejszenie nasilenia dławicy. Wykazano, że LDL-afereza skuteczniej obniża stężenie cholesterolu frakcji LDL oraz efektywniej zmniejsza ryzyko wystąpienia zdarzeń sercowo-naczyniowych niż farmakoterapia [4]. Zaawansowana miażdżyca i jej powikłania, które wystąpiły u opisanej chorej, wynikają nie tylko z podłoża genetycznego, ale także współistnienia wielu czynników ryzyka sercowo-naczyniowego, w tym nadciśnienia tętniczego, otyłości i cukrzycy. Należy podkreślić, że intensyfikacja leczenia opornego nadciśnienia tętniczego i dyslipidemii powinna zostać poprzedzona diagnostyką wtórnych przyczyn tych chorób oraz ocenie compliance. Nieprzestrzeganie zaleceń lekarskich może być główną modyfikowalną przyczyną niepowodzeń terapeutycznych.

\section{Podsumowanie}

Terapia skojarzona u pacjenta z nadciśnieniem tętniczym i ciężką hipercholesterolemią często stanowi trudne wyzwanie w codziennej praktyce kardiologicznej. Skuteczna kontrola tych dwóch najważniejszych modyfikowalnych czynników ryzyka sercowo-naczyniowego wymaga nie tylko wnikliwej diagnostyki i zindywidualizowanego leczenia, ale także współpracy ze strony pacjenta i jego rodziny, bez której nie udaje się osiągnąć wyznaczonych celów terapeutycznych.

\section{Konflikt interesów}

Autorzy pracy oświadczają, że nie zachodzi żaden konflikt interesów w związku z publikowaną pracą.

\section{Abstract}

A 61-year-old woman with a history of severe, uncontrolled arterial hypertension, coronary artery disease, heterozygous familial hypercholesterolemia (FH), metabolic syndrome and numerous comorbidities, after many percutaneous coronary interventions and vascular interventions was admitted to the hospital due to exacerbation of angina. Coronary angiography revealed hemodynamically significant stenosis in the circumflex branch and artery angioplasty with drug-eluting stent was successfully performed. Laboratory tests revealed still significantly elevated levels of LDL-cholesterol. The patient was previously treated with LDL-apheresis which has been interrupted due to a history of ischemic strokes complicated by hemiparesis and aphasia. Pharmacological treatment has been modified, control visit and resuming LDL-apheresis or PCSK-9 therapy consideration prescribed. After obtaining the improvement of compliance good control of blood pressure was confirmed. The presented case illustrates the possibility of using different therapeutic strategies in patients with $\mathrm{FH}$ and underlines the key role of compliance in the control of risk factors for cardiovascular diseases, particularly hypertension.

Key words: coronary artery disease, familial hypercholesterolemia, metabolic syndrome, hypertension, compliance

Folia Cardiologica 2017; tom 12, supl. B: B13-B17

\section{Piśmiennictwo}

1. Zdrojewski T, Bandosz P, Rutkowski M, et al. Rozpowszechnienie, wykrywanie i skuteczność leczenia nadciśnienia tętniczego w Polsce-wyniki badania NATPOL 2011. Nadciśnienie Tętnicze. 2014; 18(2): 116-117.

2. Catapano AL, Graham I, Backer GDe, et al. [2016 ESC/EAS Guidelines for the Management of Dyslipidaemias]. Kardiol Pol. 2016; 74(11): 1234-1318, doi: 10.5603/kp.2016.0157, indexed in Pubmed: 27910077.
3. Jacobson TA, Ito MK, Maki KC, et al. National lipid association recommendations for patient-centered management of dyslipidemia: part 1 - full report. J Clin Lipidol. 2015; 9(2): 129-169, doi: 10.1016/j. jacl.2015.02.003, indexed in Pubmed: 25911072.

4. Mabuchi H, Koizumi J, Shimizu M, et al. Long-term efficacy of low-density lipoprotein apheresis on coronary heart disease in familial hypercholesterolemia. Am J Cardiol. 1998; 82(12): 1489-1495, doi: 10.1016/s0002-9149(98)00692-4. 